\title{
ESTUDO DA OBTENÇÃO DE COMPOSTO A PARTIR DE LODO GERADO EM ESTAÇÃO DE TRATAMENTO DE ÁGUA A BASE DE TANINO COMO COAGULANTE
}

\author{
M. M. FURTADO, A. P. ZIMMER, J. S. MEDEIROS, H. R. A. SOUZA Jr e E. SKORONSKI \\ Universidade do Estado de Santa Catarina, Departamento de Engenharia Ambiental \\ E-mail para contato: skoronski@cav.udesc.br
}

\begin{abstract}
RESUMO - Neste trabalho foi avaliada a compostagem de lodo obtido em uma estação de reuso de água que aplica tanino como agente coagulante, no tratamento de água obtida da lavação de plástico PET. Após uma caracterização prévia em termos de relação $\mathrm{C} / \mathrm{N}$, constatou-se a necessidade de adição de um resíduo com baixa relação $\mathrm{C} / \mathrm{N}$, sendo selecionado o lodo de uma estação de tratamento de esgoto. Foram montadas leiras de compostagem com a mistura dos dois resíduos de forma a gerar condições experimentais de $\mathrm{C} / \mathrm{N}$ entre 20 e 40 e umidade de 40 a $80 \%$. Os resultados demonstram que a temperatura das leiras manteve-se sempre acima da temperatura ambiente, atingindo valores máximos de $40{ }^{\circ} \mathrm{C}$. Foi ajustado um modelo linear aos dados obtidos, sendo que os coeficientes não foram significativos e portanto os fatores testados, dentro dos níveis considerados neste trabalho, não influenciaram o processo de compostagem. Não foram detectados coliformes fecais após o processo de compostagem.
\end{abstract}

\section{INTRODUÇÃO}

Nas estações de tratamento de efluentes a redução de sólidos suspensos e colóides são realizadas através do processo de coagulação seguido de sedimentação e filtração. Para essa atividade, normalmente são utilizados coagulantes inorgânicos como sais de ferro e alumínio. Apesar de eficientes coagulantes, estes produtos geram lodos não biodegradáveis que precisam ser dispostos em aterros específicos. Segundo a NBR 10004, este lodo normalmente é classificado como classe II (Não Inerte) e deve ser disposto em aterro específico para resíduo de classe II, o que gera custos de disposição e do transporte do lodo até o aterro (Imhoff, 1998), salvo os casos em que alternativas de gerenciamento deste resíduo podem ser consideradas (Januário e Ferreira Filho, 2007).

Existe, assim, uma tendência para o desenvolvimento de novos coagulantes que gerem lodos que permitam uma variedade maior de possibilidade de valorização deste resíduo em comparação ao lodo produzido com sais de alumínio ou ferro. Alguns estudos demonstram que resíduos vegetais podem ser aplicados para o fim até aqui discutido, através da extração de tanino (Silva, 1999 e Fiorentini, 2005). A utilização do tanino como coagulante gera lodo com características biodegradáveis e ainda não consome alcalinidade na água onde o mesmo é aplicado, eliminando a necessidade de adição de alguma substância para corrigir o pH de floculação. Desta forma, a 
utilização de coagulantes com estas características pode auxiliar na diminuição de acúmulo de resíduos, sendo a compostagem uma forma potencial de tratamento e valorização do lodo gerado no processo.

A compostagem é um processo bioquímico controlado que, em condições adequadas de umidade, produz a degradação de resíduos de forma aeróbia, gerando energia para o aquecimento e eliminação de microrganismos na leira de compostagem (Epstein, 1997). Durante a compostagem esses microrganismos degradam aerobicamente parte da fração orgânica à dióxido de carbono, água e sais minerais e outra parte sofre um processo de humificação, resultando num composto estável que possui características apropriadas para a utilização como biofertilizante (Vlyssides et al., 1996; Tomati et al., 1996; Paredes et al., 2000).

Com base neste cenário, o objetivo geral deste trabalho foi avaliar a potencialidade da compostagem do lodo de uma estação de tratamento que emprega tanino como coagulante.

\section{MATERIAL E MÉTODOS}

\subsection{Amostras de lodo utilizadas}

Foi selecionado o lodo gerado de uma empresa que emprega o processo de coagulação e floculação com tanino para o tratamento do efluente obtido da lavação de PET (poli-tereftalato de etila). Esta empresa utiliza $800 \mathrm{~m} 3$ de água diários e, portanto, possui um sistema de reuso de água e também um sistema de captação de água de chuva. A Figura 1 apresenta um fluxograma com as etapas envolvidas na estação de condicionamento de água para reuso (ECR) e os diversos pontos de geração de lodo.

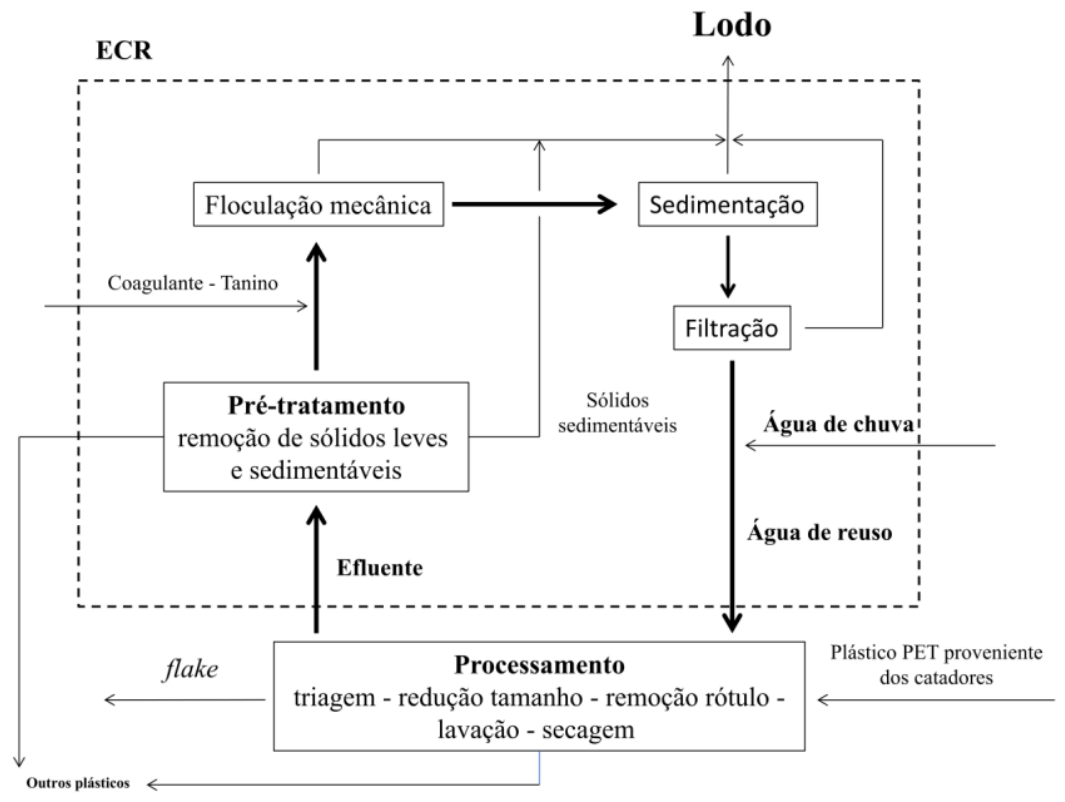


Figura 1 - Fluxograma apresentando os pontos de geração de lodo e o funcionamento da ECR.

O plástico obtido de catadores é processado para a obtenção de flakes, um material plástico que é posteriormente aplicado na obtenção de filmes de PET reciclado. Neste processo, é aplicado água para a lavação do PET e esta agrega em sua composição restos de açúcares e óleos, provenientes das garrafas, além de areia, terra e diversos microrganismos. Este efluente é destinado à ECR que apresenta as seguintes operações:

- tratamento preliminar: provido de um gradeamento para remoção de plásticos em suspensão e de caixa de areia para remoção de sólidos sedimentáveis;

- coagulação/floculação: neste processo é aplicado tanino como coagulante e a floculação é realizada em tanques prismáticos com um tempo de retenção hidráulico de 30 minutos e gradiente de velocidade constante de $50 \mathrm{~s}^{-1}$;

- sedimentação: realizada em sedimentadores de alta taxa, com taxa de aplicação superficial de 180 $\mathrm{m}^{3} . / \mathrm{m}^{2} \cdot \mathrm{dia}$

- filtração: realizada em filtros rápidos de areia por gravidade com taxa de aplicação de 240 $\mathrm{m}^{3} . / \mathrm{m}^{2} \cdot \mathrm{dia}$

- desinfecção: é aplicado cloro com concentração na ordem de $10 \mathrm{mg} / \mathrm{L}$ para eliminação dos microrganismos presentes na água;

- captação de água de chuva: uma vez que existe a perda de água no sistema juntamente com o lodo, a água é recondicionada ao sistema por meio de uma cisterna que armazena água da chuva.

Com exceção do lodo gerado no tratamento preliminar, os demais são obtidos do processo de coagulação com tanino. Existe uma produção de aproximadamente 5 toneladas/dia de lodo gerado no processo. O lodo gerado vem sendo analisado por laboratórios externos e é classificado como resíduo classe II A (NBR 10004), sendo, portanto não perigoso e não inerte. Após a coleta de uma amostra deste lodo, uma caraterização inicial em termos de relação $\mathrm{C}: \mathrm{N}$ foi realizada e então constatada a necessidade da mistura deste resíduo com outro que suprisse a inexistência de nitrogênio na sua composição, sendo então utilizado o lodo de ETE (estação de tratamento de esgoto) gerado em um processo de lodos ativados.

\subsection{Ensaios analíticos}

A caracterização dos lodos foi realizada através da determinação do teor de umidade em estufa à $105{ }^{\circ} \mathrm{C}$, da concentração de nitrogênio total Kjeldhal, da concentração de carbono total (Haug, 1993) e pela contagem de coliformes totais e fecais com a utilização de tubos múltiplos com Caldo Fluorocult LMX (Alexander, 1982). Como forma de padronização, foi definido a nomenclatura como lodo de ECR, o material obtido na estação de condicionamento para reuso e lodo de ETE o lodo obtido na estação de tratamento de esgoto. 


\subsection{Montagem e acompanhamento das leiras}

Para o processo de compostagem foram montadas leitas de seção transversal triangular de relação base:altura de 1:3, com um total de aproximadamente $5 \mathrm{Kg}$ de material (lodo de ETE misturado à lodo de ECR). A composição das leiras foi determinada através de um planejamento experimental fatorial 22 com aplicação de 3 replicatas no ponto central, totalizando 7 experimentos (Tabela 1). As leiras foram submetidas a um revolvimento com intervalos de 5 dias para promover a aeração do meio, ao longo de aproximadamente 45 dias. Após este período as leiras mantiveram-se à temperatura ambiente e iniciou-se o processo de humificação. $\mathrm{O}$ sistema foi monitorado através da temperatura, com o auxílio de termômetros instalados em três diferentes lugares da leira. A umidade também foi monitorada com o objetivo de manter esta condição constante de acordo com a condição definida no planejamento experimental (Tabela 1).

Tabela 1 - Balanço de massa para composição das leiras. Os valores entre parênteses nos lodos de ETA e ETE significam a composição em porcentagem das massas úmidas de lodos combinadas.

\begin{tabular}{|c|c|c|c|c|c|c|}
\hline \multirow{2}{*}{ Teste } & \multicolumn{2}{|c|}{ Fatores } & \multicolumn{4}{|c|}{ Massa (Kg) } \\
\cline { 2 - 7 } & C/N & $\begin{array}{c}\text { Umidade } \\
(\%)\end{array}$ & Lodo ETA & Lodo ETE & $\begin{array}{c}\text { Remoção } \\
\text { água }\end{array}$ & Final \\
\hline Leira 1 & $+1(40)$ & $+1(80)$ & $2,78(55,15 \%)$ & $2,26(44,85 \%)$ & - & 5,04 \\
\hline Leira 2 & $+1(40)$ & $-1(40)$ & $5,00(55,12 \%)$ & $4,07(44,88 \%)$ & 3,64 & 5,43 \\
\hline Leira 3 & $-1(20)$ & $+1(80)$ & $1,43(27,98 \%)$ & $3,68(72,02 \%)$ & - & 5,11 \\
\hline Leira 4 & $-1(20)$ & $-1(40)$ & $2,69(28,05 \%)$ & $6,90(71,95 \%)$ & 4,25 & 5,34 \\
\hline Leira 5 & $0(30)$ & $0(60)$ & $2,91(66,74 \%)$ & $3,71(33,26 \%)$ & 1,45 & 5,18 \\
\hline Leira 6 & $0(30)$ & $0(60)$ & $2,91(66,74 \%)$ & $3,71(33,26 \%)$ & 1,45 & 5,18 \\
\hline Leira 7 & $0(30)$ & $0(60)$ & $2,91(66,74 \%)$ & $3,71(33,26 \%)$ & 1,45 & 5,18 \\
\hline
\end{tabular}

\section{RESULTADOS E DISCUSSÃO}

A primeira etapa do trabalho consistiu na caracterização dos lodos da ECR e da ETE. O lodo da ECR apresentou uma relação C:N igual a 191,25 e teor de umidade de 87,30 \%. Já o lodo de ETE apresentou relação C:N igual a 8,78 e teor de umidade de 63,41\%. Desta forma, o lodo da ECR foi considerado o resíduo estruturante e a lodo da ETE o biosólido. Após a caracterização dos resíduos, foram construídas as leiras de compostagem. Os resultados do acompanhamento da temperatura média do processo são apresentados na Tabela 2. 
Tabela 2 - Fatores aplicados para composição das leiras e valores de temperatura das leiras ao longo do tempo e comparação com a temperatura ambiente.

\begin{tabular}{|c|c|c|c|c|c|c|}
\hline \multirow{2}{*}{ Teste } & \multicolumn{2}{|c|}{ Fatores } & \multicolumn{3}{c|}{ Temperatura $\left({ }^{\circ} \mathrm{C}\right)$} & \multirow{2}{*}{$\begin{array}{c}\text { C/N após 50 } \\
\text { dias }\end{array}$} \\
\cline { 2 - 6 } & $\mathrm{C} / \mathrm{N}$ & Umidade $(\%)$ & Média & Mínimo & Máximo & 12,7 \\
\hline Leira 1 & $+1(40)$ & $+1(80)$ & 30 & 21 & 36 & 11,2 \\
\hline Leira 2 & $+1(40)$ & $-1(40)$ & 30 & 25 & 37 & 11,8 \\
\hline Leira 3 & $-1(20)$ & $+1(80)$ & 31 & 25 & 39 & 10,8 \\
\hline Leira 4 & $-1(20)$ & $-1(40)$ & 32 & 24 & 38 & 10,9 \\
\hline Leira 5 & $0(30)$ & $0(60)$ & 31 & 22 & 36 & 9,1 \\
\hline Leira 6 & $0(30)$ & $0(60)$ & 31 & 25 & 36 & 10,8 \\
\hline Leira 7 & $0(30)$ & $0(60)$ & 33 & 25 & 40 & - \\
\hline Ambiente & - & - & 20 & 17 & 22 & \\
\hline
\end{tabular}

Comparando os valores de temperatura ambiente com os valores médios obtidos nas diversas leiras observou-se que ocorreu o processo de compostagem, uma vez que a temperatura sempre se encontrou acima da ambiente, evidenciando o processo de biodegradação aeróbia. Diversos estudos relatam picos de temperaturas próximo de $60{ }^{\circ} \mathrm{C}$ (Haug, 1993; Tomati et al., 1996 e Camargo et al., 2010) durante o processo de compostagem (fase termofílica), diferente do observado nos experimentos deste trabalho que não ultrapassaram $40{ }^{\circ} \mathrm{C}$, mantendo-se desta forma na fase mesofíla. Esta observação possivelmente está ligada ao fato de o lodo da ECR apresentar essencialmente tanino como fonte de matéria orgânica. Estes polifenóis são utilizados como esqueletos carbônicos para o processo de humificação e não como fonte de carbono para conversão a dióxido de carbono, o que efetivamente eleva a temperatura das leiras, sendo que os compostos responsáveis por este efeito (açúcares, principalmente) encontravam-se em menor quantidade. O número de coliformes totais foi

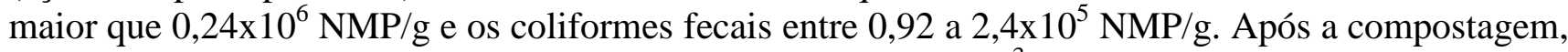
os valores de coliformes totais e fecais ficaram abaixo de $1,0 \times 10^{3} \mathrm{NMP} / \mathrm{g}$, sendo este o limite crítico microbiológico utilizado para avaliar o potencial de uso deste resíduo sem qualquer restrição, na agricultura (Ferreira et al., 1999).

Com relação a influência dos fatores (relação C:N e teor de umidade) no processo de compostagem, um modelo linear foi proposto para correlacionar os dados apresentados. No entanto, os coeficientes apresentaram um valor de $\mathrm{p}>0,05$ e portanto não são significativos, permitindo concluir que os fatores testados não influenciam no processo de compostagem. Com relação à relação C:N após 50 dias de processo (Tabela II), observou-se que houve uma perda considerável de carbono que associada com a estabilidade da temperatura em condições ambientes, demonstram que a fase de humificação teve início. Kiehl (1998) considera produto humificado para relação C:N entre 8:1 a 12:1 e entre 13:1 a 18:1 como produto semicurado ou bioestabilizado, podendo ser utilizado sem risco de causar danos às plantas. 


\section{CONCLUSÃO}

Os resultados apresentados neste trabalho demonstram que é possível realizar a compostagem de lodo de ECR a base de tanino, sendo esta uma metodologia importante para a valorização e o gerenciamento deste resíduo. Um estudo mais detalhado deve ser realizado de forma a avaliar se estas heterogeneidades das propriedades do lodo podem ser um obstáculo para a valorização deste resíduo como composto. Também deve ser aplicado o lodo no plantio de culturas para avaliar a sua capacidade de uso como fertilizante.

\section{REFERÊNCIAS}

ABNT - Associação Brasileira de Normas e Métodos, Norma Brasileira no. 10004, Classificação de Resíduos, NBR 10004.

ALEXANDER, M. Most probable number method for microbial populations. American Society of Agronomy, p. 815-820, 1982.

CAMARGO, R.; MALDONADO A. C. D.; SILVA, P. A.; COSTA, T. R. Biossólido como substrato na produção de mudas de pinhão-manso. Rev. bras. eng. agríc. ambient., v. 14, p. 1304-1310, 2010.

EPSTEIN, E. The science of composting. Pennsylvania: Technomic Publishing Company, 1997.

FERREIRA A. C.; ANDREOLI C. V.; LARA A. I. Riscos associados ao uso do lodo de esgoto. In: Uso e manejo do lodo de esgoto na agricultura. Rio de Janeiro: PROSAB, 1999.

FIORENTINI, V. Uso do tanino no processo de tratamento de água como melhoria em sistema de gestão ambiental. Dissertação de Mestrado, Universidade Federal de Santa Maria, Brasil, 2005.

HAUG, R. T. The Practical Handbook of Compost Engineering, Florida: CRC Press, 1993.

IMHOFF, K.; IMHOFF, K. R. Manual de tratamento de águas residuárias. São Paulo: E. Blücher, 1998.

JANUÁRIO, G. F.; FERREIRA FILHO, S. S. Planejamento e aspectos ambientais envolvidos na disposição final de lodos das estações de tratamento de água da Região Metropolitana de São Paulo. Eng. Sanit. Ambient., v. 12, p. 117-126, 2007.

KIEHL, E. J. Manual de Compostagem: maturação e qualidade do composto. Piracicaba, 1998.

PAREDES, C.; ROIG, A.; BERNAL, M. P.; SÁNCHEZ-MONEDERO, M. A.; CEGARRA, J. Evolution of organic matter and nitrogen during co-composting of olive mill wastewater wioth solid organic wastes. Biol. Fert. Soils, v. 32, p. 222-227, 2000. 
SILVA, S. S. T. Estudo de tratabilidade físico-química com uso de taninos vegetais em água de abastecimento e de esgoto. Dissertação (Mestrado em Saúde Pública). Escola Nacional de Saúde Pública Fundação Oswaldo Cruz , São Paulo, 87 p., 1999.

TOMATI, U.; GALLI, E.; FIORELLI, F.; PASETTI, L. Fertilisers from composting of olive-mill wastewaters. Int. Biodeter. Biodegr., v. 38, p. 155-162, 1996.

VLYSSIDES, A. G.; BOURANIS, D. L.; LOIZIDOU, M.; KARVOUNI, G. Study of a demonstration plant for the co-composting of olive-oil- processing wastewater and solid residue. Bioresource Technol., v. 56, p. 187-193, 1996. 